\title{
The effects of shifts in delay of liquid sucrose reward in thirsty rats
}

\author{
MITRI E. SHANAB, JULIA DOMINO, and SAIMI MELROSE \\ California State University, Fresno, California 93740
}

\begin{abstract}
In a two-shift experiment, four independent groups of thirsty rats received the following treatments: NNN, DDD, NDN, and DND, with each letter denoting the duration of the delay $(0$ or $30 \mathrm{sec}$ ) before receipt of the sucrose reward in each of the three phases of the experiment. While no reliable positive contrast effect was obtained in either shift phase, a significant negative contrast effect was obtained in both shift phases. The paucity of empirical data in this area hinders adequate explanatory attempts.
\end{abstract}

The study of the effects of contrasted conditions of reinforcement upon behavior has been attracting increased attention since the late 1960s (cf. Cox, 1975; Dunham, 1968). Crespi (1942) was among the first to show that both positive and negative contrast effects could occur following either an upward or downward shift in magnitude of reward. A positive contrast effect (PCE) is said to have taken place when subjects shifted from a small to a larger reward perform significantly better than control subjects experiencing the larger reward magnitude all the time. On the other hand, a negative contrast effect (NCE) is said to have occurred when subjects shifted from a large to a smaller reward perform at a markedly inferior level than control subjects receiving small reward all the time. The occurrence of either a PCE or NCE is dependent on the reinforcement conditions being shifted. Downward shifts in solid-food rewards have generally produced NCEs (Cox, 1975). However, no NCE has been reported based on single downshifts in either concentration or magnitude of liquid sucrose rewards (Goodrich, 1962; Homzie \& Ross, 1962; Ison \& Rosen, 1968; Rosen, 1966; Rosen \& Ison, 1965) or both concentration and magnitude (Barnes \& Tombaugh, 1973; Flaherty, Riley, \& Spear, 1973; Ison \& Rosen, 1968).

A PCE based on shifts in food reward has been very difficult to obtain, especially in the runway. But recently an increasing number of studies have consistently found a PCE (Mellgren, 1972; Shanab \& Biller, 1972; Shanab \& Cavallaro, 1973; Shanab, Sanders, \& Premack, 1969). In these studies the PCE was obtained when shifts in reward magnitude were introduced along with delay. This procedure was used to control for the presumed ceiling effects associated with the instrumental running response (cf. Bower, 1961). Similarly, no PCE has been reported based on single upward shifts in sucrose reward

Reprint requests should be sent to Mitri E. Shanab, Department of Psychology, California State University, Fresno, California 93740. in the runway (Flaherty et al., 1973; Goodrich \& Zaretsky, 1962; Spear, 1965).

Studies investigating shifts in water reward in the runway are scarce. Sgro and Weinstock (1963) shifted thirsty rats from 15 - and $7.5-\mathrm{sec}$ delay to immediate reward. A significant PCE was reported for those subjects shifted from 15-sec to immediate reward. Ferrell and Shanab (1975) investigated both PCE and NCE in a three-way factorial design in which thirsty rats received either $0-, 8-$, or 16 -sec delay of water reward in the preshift phase. In the shift phase, the subjects in each main group were subdivided into three groups and were either continued on the preshift delay or shifted to the other two delay intervals. Neither a significant PCE nor NCE was obtained. However, a graphical but statistically nonsignificant PCE was observed in all sections of the runway. There are no known studies which investigated contrast effects as a function of shifts in magnitude of water reinforcement.

These findings are in agreement with a number of studies using food reward. No PCE was found based on the following shifts in delay of food reward: from $15 \mathrm{sec}$ to $0 \mathrm{sec}$ (Shanab \& Biller, 1972; Shanab \& McCuistion, 1970), from 20 to 0 sec (Cox \& Black, 1975), and from 30 to $10 \mathrm{sec}$ (McCain, Boodeé, \& Lobb, 1977; McCain, Lobb, Almand, \& Leek, 1976; Shanab \& Cavallaro, 1973). All the preceding studies utilized the runway. Studies that used shifts in delay in nonrunway situations have also failed to obtain a PCE as well as NCE (Harker, 1956; Logan, 1952; Sgro, Glotfelty, \& Moore, 1970). The evidence for NCE based on shifts in delay of food reward in the runway is equivocal. When a shift was made from 0 - to $15-\mathrm{sec}$ delay, negative contrast was obtained in two studies (Shanab \& Biller, 1972; Shanab \& McCuiston, 1970). However, three other studies which used the same delay intervals failed to obtain a significant NCE (Mackintosh \& Lord, 1973; Shanab, 1971; Shanab \& Cavallaro, 1973). Similarly, no NCE was reported when rats were shifted from 0 - to 30-sec delay regardless of the magnitude ( 1 or 22 pellets) of the reward received (Shanab 
\& Cavallaro, 1973). While McCain et al. (1976) and McHose and Tauber (1972) found a significant NCE with a shift from 10- to 30-sec delay, McCain et al. (1977) failed to obtain a significant NCE based on a shift in the same delay intervals.

Thus, it appears that it is difficult to obtain contrast effects based on single shifts in either magnitude or delay of either food or liquid reinforcers. Recently, Benefield, Oscos, and Ehrenfreund (1974), using food reward, reported a significant PCE based on a doubleshift procedure similar to the one used earlier by Crespi (1942). Subjects in the double-shift procedure are either shifted from large to small before being shifted back to large reward or from small to large before being shifted to small reward again. When such a procedure was employed, Shanab, France, and Young (1976) reported significant PCE and NCE based on appropriate shifts in liquid sucrose reward.

The purpose of the present study was to replicate the previous double-shift PCE and NCE findings using shifts in delay of sucrose reward. If, as Benefield et al. (1974) stated, experience with the less favorable reinforcement condition is a sufficient condition for the emergence of PCE, then a comparable PCE should be obtained in subjects first shifted from 0 - to $30-\mathrm{sec}$ delay, then back to 0 -sec delay. Similarly, subjects shifted to 0 - from 30-sec delay before receiving 30-sec delay again should show a significant $\mathrm{NCE}$.

\section{METHOD}

\section{Design}

A three-phase study was run. In Phase 1 two randomized groups consisting of 24 subjects each were assigned to either a nondelay condition (N) or a 30 -sec delay condition (D). In Phase 2 each group was divided in half; subgroups from each main group continued to receive Phase 1 delay conditions (N-N, D-D), while the other subgroups were shifted to the other delay condition (N-D, D-N). In Phase 3 the experimental subjects were again shifted to Phase 1 conditions.

\section{Subjects}

The subjects were 48 male albino rats of the Sprague-Dawley strain, approximately 100 days old at the beginning of the experiment.

\section{Apparatus}

The $1.5-\mathrm{m}$ unpainted redwood runway was the same as that described earlier (Ferrell \& Shanab, 1975). An additional fixture to the runway apparatus was a small metal plate $(2.5 \mathrm{~cm}$ square $)$ located on the far wall of the goalbox. The metal plate surrounded an aperture located $4.2 \mathrm{~cm}$ from the goalbox floor. Through the aperture, a drinking tube was presented automatically to the subject after the delay interval and then retracted at the end of the access time. During each delay interval, the subject was confined to the goalbox by the use of a second guillotine door.

\section{Procedure}

Upon arrival from the supplier, the rats were housed individually and handled approximately $2 \mathrm{~min} /$ day for 14 days. Following the handling period, the subjects received a 23-h deprivation schedule for 5 days and were then placed on the $23^{1 / 2}-\mathrm{h}$ deprivation which was maintained for the remainder of the experiment. After a total of 14 days of water deprivation, subjects were given 3 days of exploration, each session lasting $90 \mathrm{sec} / \mathrm{subject.} \mathrm{On} \mathrm{Day} 1$ of exploration, both guillotine doors were left open and the equipment was turned off. On Days 2 and 3 all equipment was turned on and the guillotine doors operated as during a regular trial. No sucrose solution was provided in the goalbox during the exploration period. However, the subjects were familiarized outside the runway with the $18 \%$ sucrose solution later to be used as the reinforcer. On the following 2 days, operant levels were obtained by measuring the time taken by each subject to cross the entire runway. The subjects were then randomly assigned to either the delay or nondelay condition and Phase 1 started. On Day 1 of Phase 1 each subject received one trial. On Day 2 the subjects received two trials; on Day 3 and for the remainder of the experiment, all subjects were given three trials a day. Subjects in the nondelay condition received reinforcement immediately after the last photobeam, located in the goalbox, was broken. For subjects in the delay condition, presentation of the sucrose solution was delayed $30 \mathrm{sec}$. Throughout the experiment the reinforcer for all subjects consisted of 20 -sec access to an $18 \%$ solution of sucrose which was made by mixing $18 \mathrm{~g}$ of commercial sugar with $100 \mathrm{cc}$ of tap water. The subjects were run in groups of six, with an intertrial interval of 5-6 min. Each subject received $30-\mathrm{min}$ access to water in its home cage at least $1 / 2 \mathrm{~h}$ after its last daily trial. Phase 1 lasted for 14 days.

In Phase 2 subjects of both the nondelay and delay conditions were matched on their terminal performance in Phase 1 and divided into two equal groups. One subgroup from each main group was continued on Phase 1 conditions, while the other two subgroups were shifted to the other delay condition. In Phase 3 the shifted subjects were returned to their Phase 1 delay or nondelay condition, while the controls were left unshifted. Phases 2 and 3 lasted for 9 days each.

\section{RESULTS}

All analyses are based on mean total reciprocal times.

As Figure 1 shows, the delayed subjects ran slower than the immediately rewarded subjects in Phase 1. This difference was significant over the last 3 days of Phase $1[F(1,46)=5.47, p<.05]$. Figure 1 also shows that subjects shifted from a $30-\mathrm{sec}$ delay to immediate reinforcement showed a gradual increase in running speed which, beginning with Day 4 and until the last day of Phase 2, exceeded the level of the control subjects. On the other hand, it appears that the subjects shifted from immediate to delayed reward showed a

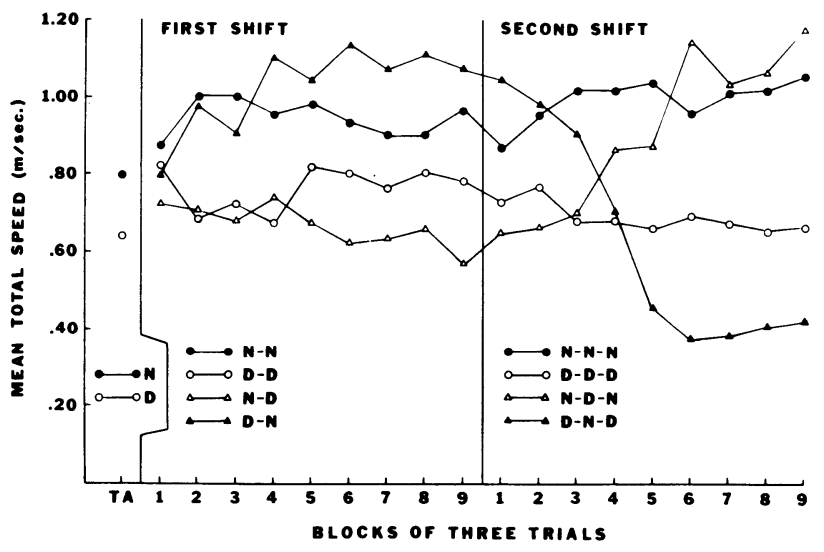

Figure 1 
more abrupt change, in that the shifted subjects undershot the level of their controls beginning with the Day 2 of the shift and continued to perform at a lower level until the end of Phase 2. A two-way analysis of variance performed on the mean speeds over Blocks 5-9 yielded significant Phase 1 effects $[F(1,44)=7.51$, $\mathrm{p}<.01]$, as well as Phase 2 effects $[\mathrm{F}(1,44)=27.55$, $\mathrm{p}<.001]$. The interaction effect between the two phases was not significant $(F<1)$. Because the absence of interaction effects does not necessarily mean that no contrast effects have occurred, appropriate individual comparisons were made to test for both the PCE and NCE (actually the presence of an interaction effect in shift studies often implies the occurrence of a unidirectional contrast effect). A significant NCE was obtained $[F(1,44)=4.24, p<.05]$, but the PCE failed to reach significance $[F(1,44)=3.30, p<.05]$. As can be seen in Figure 1, when subjects were returned to their original reinforcement conditions, they showed gradual increases and decreases in speeds that eventually overshot and undershot the level of the controls. The overshooting was apparently not as pronounced as the undershooting effect. The results of a two-way analysis of variance over Blocks 5-9 yielded significant Phase 2 effects $[F(1,44)=13.75, p<.001]$, as well as Phase 3 effects $[F(1,44)=138.28, p<.001]$. A significant interaction effect was obtained between the two main effects $[F(1,44)=5.02, p<.05]$. An $F$ test of simple effects was performed to test for the differences between Groups NDN and NNN (PCE) and Groups DND and DDD (NCE). No significant PCE was found $(F<1)$. However, a significant NCE was obtained $[\mathrm{F}(1,44)=$ $6.19, \mathrm{p}<.025]$.

\section{DISCUSSION}

The occurrence of a significant NCE based on a double shift in delay of sucrose reward is in agreement with the similar finding of a NCE based on a double shift in magnitude of sucrose reward (Shanab et al., 1976). However, the absence of a corresponding PCE is puzzling. Apparently, under the conditions of the present study, the NCE is a more reliable phenomenon than the PCE, for it appeared in both shift phases. While the occurrence of a NCE in this study is consistent with similar findings based on downshifts in magnitude of food reward (Cox, 1975; Shanab, Kong, \& Domino, 1977), shifts in delay of food reward have either resulted in a significant NCE (McCain et al., 1976; McHose \& Tauber, 1972; Shanab \& Biller, 1972) or failed to show the effect (Mackintosh \& Lord, 1973; McCain et al., 1977; Shanab \& Cavallaro, 1973). Similarly, no NCE has been obtained based on shifts in delay of water reward (cf. Ferrell \& Shanab, 1975).

The ease with which NCE was obtained in this study is intriguing in view of the traditional difficulty of obtaining a NCE based on a single shift in either magnitude or concentration of liquid sucrose reward or in delay of water reward in the runway. As indicated earlier, even downshifts in delay of food reward have produced inconsistent results. On the other hand, the absence of a PCE based on a double shift was not expected but is in agreement with at least one study in which multiple shifts in delay of food reward were made (McCain et al., 1976). The present dilemma could be partially understood in terms of the robustness of the NCE relative to the PCE. While special control techniques have been devised (cf. Shanab, Birnbaum, \& Cavallaro,
1974) and special designs used (cf. Benefield et al., 1974) to produce the PCE, the NCE has been rather consistently obtained, especially when downshifts in magnitude of food reward were made. Moreover, the effect appears during the first shift. Benefield et al. (1974) suggested that experience with frustration was a sufficient condition for both NCE and PCE. In the double-shift design, the frustration experienced during the downshift phase is presumed to persist in the upshift phase. It is conceivable that such frustrative experience would be attenuated by the sudden shift from a less favorable to a more favorable condition. This would mean that not as much frustration drive is available to facilitate the PCE as the NCE. During downshifts subjects are exposed to frustration-producing operations, thus the magnitude of frustration should be greater than that during upshifts preceded by downshifts. The present results are therefore not surprising, especially in view of the paucity of repeated-shift designs. Moreover, it should be noted that this is probably the first runway study in which delay of liquid sucrose reward was manipulated in a shift design. Among other factors, failure to obtain a significant PCE could be due to certain characteristics in the delay variable, the sucrose variable, or both, or to the fact that two shifts were insufficient to produce the desired effect. Thus, until more work is carried out in this area, it seems premature to conjecture about the reasons for the fragile PCE, or even the reliable NCE, observed in this study.

\section{REFERENCES}

Barnes, W., \& Tombaugh, T. N. Another failure to obtain negative incentive contrast following reductions in sucrose reward. Psychological Reports, 1973, 33, 801-802.

Benefield, R., Oscos, A., \& Ehrenfreund, D. Role of frustration in successive positive contrast. Journal of Comparative and Physiological Psychology, 1974, 86, 648-651.

Bower, G. H. A contrast effect in differential conditioning. Journal of Experimental Psychology, 1961, 62, 196-199.

Cox, W. M. A review of recent incentive contrast studies involving discrete-trial procedures. Psychological Record, 1975, 25, 373-393.

Cox, W. M., \& Black, R. W. Shifts in magnitude of delayed and immediate reward. Bulletin of the Psychonomic Society, 1975, 6, 35-38.

Crespi, L. P. Quantitative variations of incentive and performance in the white rat. American Journal of Psychology, 1942, 55, 467-517.

Dunham, P. J. Contrasted conditions of reinforcement: A selective critique. Psychological Bulletin, 1968, 69, 295-315.

Ferrell, H. J., \& Shanab, M. E. Contrast effects as a function of shifts in delay of water reward. Bulletin of the Psychonomic Society, 1975, 5, 417-420.

Flaherty, C. F., Riley, E. P., \& Spear, N. E. Effects of sucrose concentration and goal units on running behavior in the rat. Learning and Motivation, 1973, 4, 163-175.

Goodrich, K. P. Supplementary report. Running speed as a function of sucrose concentration in a prior free-drinking period. Psychological Reports, 1962, 11, 528-530.

Goodrich, K. P., \& ZaRetsky, H. Running speed as a function of sucrose concentration in a prior free-drinking period. Psychological Reports, 1962, 11, 463-468.

HARKER, G. S. Delay of reward and performance of an instrumental response. Journal of Experimental Psychology, 1956, 51, 303-310.

Homzie, M. J., \& Ross, L. E. Runway performance following a reduction in the concentration of a liquid reward. Journal of Comparative and Physiological Psychology, 1962, 55, 1029-1033.

IsoN, J. R., \& Rosen, A. J. Extinction and reacquisition performance as a function of sucrose-solution rewards and numbers of acquisition trials. Psychological Reports, 1968, 22, 375-379. 
LogAN, F. A. The role of delay of reinforcement in determining reaction potential. Journal of Experimental Psychology, 1952, 43, 393-399.

MAckintosh, N. J., \& LoRD, J. Simultaneous and successive contrast with delay of reward. Animal Learning \& Behavior, 1973, 1, 283-286.

McCain, G., Boodé, A., \& Loвb, M. Extended training: Delay of reward. Bulletin of the Psychonomic Society, 1977, 9, 111-112.

McCain, G., Lobb, M., Almand, W., \& Leek, D. Delay of reinforcement: Extended training, and multiple shifts. Bulletin of the Psychonomic Society, 1976, 7, 539-541.

McHose, J. H., \& TAUber, L. Changes in delay of reinforcement in simple instrumental conditioning. Psychonomic Science, 1972, 27, 291-292.

Mellgren, R. L. Positive and negative contrast effects using delayed reinforcement. Learning and Motivation, 1972, 3, 185-193.

Rosen, A. J. Incentive-shift performance as a function of magnitude and number of sucrose rewards. Journal of Comparative and Physiological Psychology, 1966, 62, 487-490.

Rosen, A. J., \& Ison, J. R. Runway performance following changes in sucrose rewards. Psychonomic Sicence, 1965, 2, 335-336.

Sgro, J. A., Glotfelty, R. A., \& Moore, B. D. Delay of reward in the double alleyway: $A$ within-subjects vs. between-subjects comparison. Journal of Experimental Psychology, 1970, 84, 82-87.

Sgro, J. A., \& Weinstock, S. Effects of delay on subsequent running under immediate reinforcement. Journal of Experimental Psychology, 1963, 66, 260-263.

Shanab, M. E. Positive transfer between nonreward and delay. Journal of Experimental Psychology, 1971, 91, 98-102.
Shanab, M. E., \& Biller, J. D. Positive contrast in the runway obtained following a shift in both delay and magnitude of reward. Learning and Motivation, 1972, 3, 179-184.

Shanab, M. E., Birnbaum, D. W., \& Cavallaro, G. Positive contrast obtained in reacquisition following interpolation of nonreinforced or partially reinforced trials. Learning and Motivation, 1974, 5, 258-271.

Shanab, M. E., \& Cavallaro, G. Transfer between nonreward and delay of reward following minimal acquisition training. Animal Learning \& Behavior, 1973, 1, 179-182.

Shanab, M. E., France, J., \& Young, T. Positive and negative contrast effects obtained following shifts in liquid sucrose reward in thirsty rats. Animal Learning \& Behavior, 1976, 4, 9-12.

Shanab, M. E., Kong, J., \& Domino, J. Incentive contrast following repeated shifts in magnitude of food reward in the Skinner box. Bulletin of the Psychonomic Society, $1977,9,47-50$.

Shanab, M. E., \& McCuistion, S. Effects of shifts in magnitude and delay of reward upon runway performance in the rat. Psychonomic Science, 1970, 21. 264-266.

Shanab, M. E., Sanders, R., \& Premack, D. Positive contrast in the runway obtained with delay of reward. Science, 1969, 164, 724-725.

SpEAR, N. E. Replication report: Absence of a successive contrast effect on instrumental running behavior after a shift in sucrose concentration. Psychological Reports, 1965, 16, 393-394.

(Received for publication June 12, 1977.) 